\title{
The implications of changes in postgraduate medical education - the role of the College
}

Five speakers contributed to the Education Committee's Open Forum which was held at the College on 2 October 1991. The implications of changes in postgraduate medical education and the role of the College were discussed by a Postgraduate Dean, a Regional Adviser, a Psychiatric Tutor, a representative of the CTC and the Chairman of Programmes and Meetings Committee.

Précis of four of the papers follow. The presentation of the Tutor has been superseded by further changes and he would prefer to address these in a contribution to the Psychiatric Bulletin in a future issue.

\section{Postgraduate medical education}

Professor Sydney Brandon, Postgraduate Dean, Leicester

The new arrangements are set out in EL(90)179 and the NHS Management Executive unnumbered paper in the Working for Patients series entitled Postgraduate and Continuing Medical and Dental Education. The essential changes are designed to produce a system which is professional and accountable.

In each region there should be a directorate of postgraduate education headed by a postgraduate dean accountable to the regional health authority for manpower and financial management and to the university in educational matters. Each dean is likely to have associate deans who perhaps take responsibilty for specific areas such as pre-registration house officers or part-time training.

For each major unit there will be a postgraduate clinical tutor responsible for overviewing the education of all medical staff within the unit.

There has been a problem in attempting to identify the actual costs of postgraduate medical education. As an approximation, all units were asked to identify actual expenditure in 1990/91 and this sum upgraded for inflation was identified and ring-fenced for 1991/92.

By convention established in $\mathrm{E}(90) 179$ postgraduate medical education is taken to refer to the training grades and continuing medical education (CME) to permanent staff including consultants, staff grades, associate specialists, clinical assistants and so on. All medical staff will require CME.

From region, through the postgraduate dean, funds are passed to units where the postgraduate clinical tutor is the budget holder. In collaboration with the unit general manager he is responsible for study leave for all grades of staff and appropriate educational provision for the unit. The funds made available are under three headings-study leave, costs of postgraduate centres, and capital charges on designated educational accommodation.

In future years study leave and the costs of continuing medical education will be funded from the unit clinical service contracts. If the study leave allocation is insufficient, and it will be, the unit must be persuaded to increase its costs.

Postgraduate medical education will be funded centrally, and presumably regions must bid to the Department of Health for any increase.

Psychiatry has been in advance of many disciplines in recognising psychiatric tutors and giving them a clear role, in demanding university involvement, and in providing formal educational courses. Many psychiatric tutors receive modest remuneration through the university but from regional funds. Now other specialities are beginning to specify their requirements and new funding will be required.

Those psychiatric tutors in the larger mental illness units may now become postgraduate clinical tutors on remuneration or dedicated time equivalent to up to two sessions-one of which may be paid above the full-time contracted salary. Smaller units and those within general hospitals may not justify clinical tutor status and we need to maintain psychiatric speciality tutors. It is unlikely that new psychiatric tutors will be funded though some administrative support might be provided. We also need to press for recognition of the responsibilities carried by course organisers.

Rotational schemes are a matter for concern, especially where several units or even regions are involved. There is pressure on the Department of Health to allocate registrar and senior registrar funding, as well as contracts, to regions and hopefully to postgraduate deans. This would eliminate most of the worries around rotational schemes.

Library facilities are also funded by the deans and with increasing pressure for separate libraries for nurses and other staff some rationalisation is inevitable. It is probably more sensible to fund and maintain 'Health Service' libraries rather than separate facilities for departments, units or professions. Such centralised libraries would service several hospitals and have linked facilities including reprint and loan deliveries, CD-ROM equipment and so on. If such central services are established College requirements may need to be modified. 
It is easy to be glum about reorganisation but we must seize opportunities which are offered. One clear benefit will eventually be a professional, accountable and properly trained staff providing educational services for medicine.

\section{The Regional Adviser's tale}

Dr Peter Maddocks, Regional Adviser for Oxford Region

The pressures of Achieving a Balance have led to the creation of regional training schemes for registrars in Oxford and in other regions. The speciality training committee, which was set up to implement the changes, has evolved into a system where the regional coordinating tutor chairs a committee of all the psychiatric tutors and organises the registrar rotation. The speciality training committee also arbitrates on problems that cannot be solved between the tutors. Since registrar contracts remain at region so regional officers can provide some administrative support for the regional coordinating tutor and this tutor is appointed by the postgraduate dean on the recommendation of the speciality training committee after consultation with the professor. While the government is trying to devolve training down to units, Achieving a Balance is causing training to be organised regionally rather than by district.

It seems likely that there will be modifications. One is that district clinical tutors will continue to chair a district postgraduate medical education committee of speciality tutors and that the unit tutors will not come into being. Another is that the regional study leave committee will continue to sit. In the past the study leave committee has overspent its budget and this seems less likely to be allowed in the future. In the past an overspend has been covered by region but this is unlikely to happen when the budget is controlled by the dean. He will want value for money, and this is already leading to the creation of local courses. It remains uncertain how regional advisers will communicate with the regional postgraduate medical education committee, but as the dean receives minutes of the local higher psychiatric training committees which oversee senior registrar training as well as the speciality training committee and also chairs senior registrar appointment committees and reviews, the regional adviser has opportunity to give advice on College standards.

In many ways the College has a good grip on education standards. It has criteria for appointees, has a veto on appointment committees, has laid down requirements for training programmes and a system of inspection for every training grade and all this does not depend on the district clinical tutor postgraduate medical education system. However, it is and will be this system which controls the finance for study leave, libraries, courses and should also support the administrative costs incurred by psychiatric tutors and the honoria for those fortunate enough to receive them.

For the new structures to be workable, the budget given to postgraduate deans should be realistic, and there must be mechanisms whereby College advice can be received by the structure.

\section{The response of psychiatric trainees to the implications of changes in postgraduate medical education}

\author{
Dr ToNI Lock, Collegiate Trainees Committee \\ Regional Representative for Merseyside \\ (presented by Dr BEN GREEN)
}

Psychiatrists have several defined roles.

The traditional medical clinician who is an expert in the diagnosis and treatment of mental illness. The emphasis here is on secondary- and tertiary-care clinical skills. Psychiatrists have an important role to play in advising purchasing authorities, GP fundholders and directors of public health about what is needed in terms of mental health care.

The leader of multidisciplinary teams caring for day and in-patients.

The psychiatric expert in a community-based multidisciplinary team.

The medical executive, involved in the planning, co-ordination and administration of mental health resources.

Teaching, audit, and research.

Teaching others.

The 'quality control' guidelines for clinical experience laid down by the College ensure that, by the time trainees complete their higher training, they will be expert clinicians and in a position to teach others these skills.

Our trainers are presently grappling with audit, NHS management and community care, and there is, as yet, little quality control over the experience currently gained in these areas.

Trainees, with 30 working years ahead of them, cannot afford to 'opt out'. They must realise that they need to develop an aptitude in a number of areas quite far removed from clinical medicine, and that the control they will have over the delivery of mental health care in the future depends on the choices they make now.

The Collegiate Trainees Committee (CTC) has organised several educational meetings which have addressed these issues. The CTC working party report on training in general practice for basic trainees makes interesting reading, as does the suggestion for a 'Core Curriculum for Management 
Training', an idea put forward by Gadd and England.

Trainees have a legitimate educational right to suggest that changes be made to training slots in regional training rotations, and local scheme organisers could aid the process of change by recognising the need for reallocation or redefinition of existing training slots so as to provide an adequate number of posts which offer practical 'hands on' experience in these new priority areas.

A College directive addressing quality management and community care experience is urgently needed. Trainers and senior registrars clearly need to be enlightened as to what sort of management training junior trainees require, and how and when to provide this experience.

\section{The Programmes and Meetings Committee's role}

Professor CoRnelius Katona, Chairman, Programmes and Meetings Committee

The Programmes and Meetings Committee is committed to providing educational opportunities to trainees and senior registrars in psychiatry as well as contributing to the continuing medical education of consultants. The Maudsley Bequest lectures which provide presentations of review topics by researchers active in the field and the opportunity to hear research presentations at topic-based symposia within the regular College meetings are also relevant to trainees both didactically and in stimulating research-orientated thinking.

Opportunity is also provided for trainees and senior registrars to present their own research findings as free oral communications and as posters. Such contributions are only accepted subject to review by the Short Papers Committee.

The opportunity presented within College meetings to present research should be seen as part of the College's overall concern to foster research training within psychiatry. It clearly needs to be supplemented by formal teaching in research methods and the availability of research supervision for trainees and senior registrars.

In recent years the Programmes and Meetings Committee has also incoporated workshop sessions within the Quarterly Meetings with considerable success. It is intended that this workshop approach be used increasingly as part of a commitment to continuing medical education.

It is clearly important that trainee senior registrars and consultants alike continue to be able to attend College meetings. We are also committed, however, to making College meetings self-financing. Although registration fees are waived for speakers and poster presenters they still have to find funding for their transport and possibly accommodation and need also to obtain study leave. The ability to obtain these may be threatened by the new studyleave funding arrangements. The availability and funding of study leave for consultants may also be under threat, particularly if the study leave funding "pool" faces competing bids from locally organised courses including those in management. Attendance at College meetings should be seen as an entirely legitimate claim on study leave funding for trainees, as a vital part of higher training for senior registrars and as very important for the continuing education of consultant psychiatrists. 